\title{
INFLUENCE OF AGING AND STRAIN ON THE STRUCTURE AND MECHANICAL PROPERTIES OF CHROMIUM-ZIRCONIUM BRONZE
}

\author{
N. Yu. Frolova ${ }^{1}$, V. I. Zeldovich ${ }^{1 *}$, I. V. Khomskaya ${ }^{1}$, A. E. Kheifets ${ }^{1}$, E. V. Shorokhov ${ }^{2}$ \\ ${ }^{I}$ M.N. Miheev Institute of Metal Physics of Ural Branch of Russian Academy of Sciences, 18 S. Kovalevskoy st., \\ Ekaterinburg, Russian Federation \\ ${ }^{2}$ Federal State Unitary Enterprise "Russian Federal Nuclear Center-Academician E.I. Zababakhin All-Russian \\ Research Institute of Technical Physics", 13 Vasiliev st., Snezhinsk, Chelyabinsk Region, Russian Federation
}

*Corresponding author. E-mail: zeldovich@imp.uran.ru; address for correspondence: 18, ul. S. Kovalevskoy, 620990, Ekaterinburg, Russian Federation. Tel.: +7 3433783554

The influence of aging and deformation by dynamic channel-angular pressing (DCAP) on the change of the structure and mechanical properties of $\mathrm{Cu}-0.14 \% \mathrm{Cr}-0.04 \% \mathrm{Zr}$ low-alloy chromium-zirconium bronze has been studied. It is shown that, under DCAP and subsequent aging, the studied bronze suffers the decomposition of the alpha-solid solution accompanied by the precipitation of nanosized particles of chromium and the copper-zirconium phase. This hardens the bronze and increases its thermal stability. A substantial increase in the mechanical properties of the bronze after DCAP and subsequent aging has been found. Thus, ultimate strength is increased 2.8 times and yield stress is increased 5.1 times as compared with the initial hardened condition, satisfactory plasticity being maintained.

Keywords: chromium-zirconium bronze, high-strain-rate deformation, aging, submicrocrystalline structures, nanosized particles, yield stress, ultimate strength, microhardness.

DOI: $10.17804 / 2410-9908.2015 .5 .099-108$

\section{References}

1. Olshansky N.A. Svarka v mashinostroenii. Spravochnik. T. 1. [Welding in Mechanical Engineering. Handbook]. M., Mashinostroenie Publ., 1978, 501 p. (In Russian).

2. Osintsev O.E., Fedorov V.N. Med i mednye splavy. Otechestvennye i zarubezhnye marki [Copper and Copper Alloys]. M., Mashinostroenie Publ., 2004, 336 p. (In Russian).

3. Valiev R.Z., Aleksandrov I.V. Obyomnye nanostrukturnye metallicheskie materialy: poluchenie, struktura i svoistva [Bulk Nanostructured Metallic Materials: Production, Structure and Properties]. M., IKTS "Akademkniga" Publ., 2007, 398 p. (In Russian).

4. Vinogradov A., Patlan V., Suzuki G., Kitagawa K., Kopylov V.I. Structure and Properties of ultra-fine grain $\mathrm{Cu}-\mathrm{Cr}-\mathrm{Zr}$ alloy produced by equal-channel angular pressing. Acta Materialia, 2002, Vol. 50 iss 7, pp. 1639-1651. DOI: 10.1016/S1359-6454(01)00437-2.

5. Shan'gina D.V., Bochvar N.R., Dobatkin S.V. Structure and properties of Cu-Cr alloys subjected to shear under pressure and subsequent heating. Russian Metallurgy (Metally), 2010, vol. 2010, iss. 11, pp. 1046-1052. DOI: 10.1134/S0036029510110091.

6. Shan'gina D.V., Maksimenkova Yu.M., Bochvar N.R., Dobatkin S.V. Behavior of an ultrafine-grained $\mathrm{Cu}-\mathrm{Zr}$ alloy in heating. Russian Metallurgy (Metally), 2011, vol. 2011, iss. 11, pp. 1069-1073. DOI: 10.1134/S0036029511110085.

7. Sennikova L.F., Davidenko A.A., Spuskaniuk V.Z., Dmitrenko V.Yu., Zakoretskaya T.A. Impact of the deformation-heat treatment on the mechanical and functional properties of $\mathrm{Cu}-\mathrm{Cr}-\mathrm{Zr}$ alloy. Scientific and Technical Journal "Voprosy Materialovedeniya", 2013, no 4 (76), pp. 35-42.

8. Melekhin N.V., Chuvildeev V.N. Effect of equal-channel angular pressing on the precipitation of particles in the $\mathrm{Cu}-\mathrm{Cr}-\mathrm{Zr}$ alloy. Fizika Tverdogo Tela. Vestnik Nizhegorodskogo Universiteta, 2011, no 5 (1), pp. 55-61. (In Russian). 
9. Shakhova I., Yanushkevich Z., Fedorova I., Belyakov A., Kaibyshev R. Grain refinement in a $\mathrm{Cu}-\mathrm{Cr}-\mathrm{Zr}$ alloy during multidirectional forging. Materials Science and Engineering: A, 2014, vol. 606, pp. 380-389. DOI: 10.1016/J.MSEA.2014.03.116.

10. Islamgaliev R.K., Nesterov K.M., Valiev R.Z. Structure, strength, and electric conductivity of a $\mathrm{Cu}-\mathrm{Cr}$ copper-based alloy subjected to severe plastic deformation. The Physics of Metals and Metallography, 2015, vol. 116, iss. 2, pp. 209-218. DOI: 10.1134/S0031918X14090063.

11. Shorokhov E.V., Zhgilev I.N., Valiev R.Z. Sposob dinamicheskoy obrabotki materialov [A Method for Dynamic Processing of Materials]. Patent RF, no. 2283717, 2006. (In Russian).

12. Zel'dovich V.I., Frolova N.Yu., Zhgilev I.N., Kheifets A.E., Khomskaya I.V., Gundyrev V.M. High-strain-rate deformation of titanium using dynamic equal-channel angular pressing. The Physics of Metals and Metallography, 2008, vol. 105, iss. 4, pp. 402-408. DOI: $10.1134 / \mathrm{S} 0031918 \mathrm{X} 08040145$.

13. Zel'dovich V.I., Shorokhov E.V., Frolova N.Yu., Zhgilev I.N., Kheifets A.E., Khomskaya I.V., Nasonov P.A., Ushakov A.A. Structure of titanium after dynamic channel angular pressing at elevated. The Physics of Metals and Metallography, 2009, vol. 108, iss. 4, pp. 347-352. DOI: 10.1134/S0031918X09100044.

14. Brodova I.G., Shirinkina I.G., Antonova O.V., Shorokhov E.V. Formation of a submicrocrystalline structure upon dynamic deformation of aluminum alloys. Materials Science and Engineering A, 2009, vol. 503, pp. 103-105. DOI: 10.1016/j.msea.2007.12.060.

15. Zel'Dovich V.I.,Khomskaya I.V.,Frolova N.Y.,Kheifets A.E.,Shorokhov E.V.,Nasonov P.A. Structure of chromium-zirconium bronze subjected to dynamic channel-angular pressing and aging. The Physics of Metals and Metallography, 2013, vol. 114, iss. 5, pp. 411-418. DOI: $10.1134 / \mathrm{S} 0031918 \mathrm{X} 13050141$.

16. Zel'dovich G.V., Frolova N.Yu.,Khomskaya I.V., Kheifets A.E., Shorokhov E.V., Nasonov P.A. Structure and microhardness of chromium-zirconium bronze subjected to severe plastic deformation by dynamic channel-angular pressing and rolling. The Physics of Metals and Metallography, 2014, vol. 115, iss. 5 pp. 465-470. DOI: 10.1134/S0031918X14050159. 
Подана в журнал: 16.09 .2015

УДК 669.3:539.89:539.25

DOI: $10.17804 / 2410-9908.2015 .5 .099-108$

\title{
ВЛИЯНИЕ СТАРЕНИЯ И ДЕФОРМАЦИИ НА СТРУКТУРУ И МЕХАНИЧЕСКИЕ СВОЙСТВА ХРОМОЦИРКОНИЕВОЙ БРОНЗЫ
}

\author{
Н.Ю. Фролова ${ }^{1}$, В.И. Зельдович ${ }^{1 *}$, И.В. Хомская ${ }^{1}$, А.Э. Хейфец ${ }^{1}$, Е.В. Шорохов ${ }^{2}$ \\ ${ }^{1}$ Федеральное государственное бюджетное учреждение науки Институт физики металлов имени \\ М.Н. Михеева Уральского отделения Российской академии наук, ул. С. Ковалевской, 18, Екатеринбург, \\ Российская Федераичия \\ ${ }^{2}$ Федеральное государственное унитарное предприятие «Российский Федеральный Ядерный Центр - \\ Всероссийский научно-исследовательский институт технической физики имени академика Е. И. Забабахина, \\ ул. Васильева, 13, Снежинск, Челябинская область, Российская Федерация \\ *Ответственный автор. Электронная почта: zeldovich@imp.uran.ru; адрес для переписки: ул. С. Ковалевской, 18, \\ 620990, Екатеринбург, Российская Федерация. Телефон: +7 (343) 378-35-54
}

Исследовано влияние старения и деформации методом динамического канальноуглового прессования (ДКУП) на изменения структуры и механических свойств низколегированной хромоциркониевой бронзы $\mathrm{Cu}-0,14 \% \mathrm{Cr}-0,04 \% \mathrm{Zr}$. Показано, что при ДКУП и последующем старении в исследуемой бронзе происходит распад $\alpha$-твердого раствора с выделением наноразмерных частиц хрома и медноциркониевой фазы. Это приводит к упрочнению бронзы и повышению ее термической стабильности. Установлено существенное повышение механических свойств исследуемой бронзы после ДКУП и последующего старения. Так, предел прочности увеличивается в 2,8 раза, предел текучести - в 5,1 раза, по сравнению с исходным закаленным состоянием, при сохранении удовлетворительной пластичности.

Ключевые слова: хромочиркониевая бронза, высокоскоростная деформация, старение, субмикрокристаллические структуры, наноразмерные частиџы, предел текучести, предел прочности, микротвердость.

\section{1. Введение}

Хромоциркониевые бронзы находят широкое применение в электротехнике [1, 2]. Они должны иметь высокие и стабильные физико-механические свойства и выдерживать контактные нагрузки без существенного пластического деформирования. Легирование хромом (до 0,5 мас. \%) приводит к упрочнению при последующем старении, а легирование цирконием (до 0,2 мас. \%) повышает температуру рекристаллизации, что позволяет расширить температурный интервал эксплуатации материала [2]. Создание субмикрокристаллической (СМК) и нанокристаллической структуры повышает служебные характеристики бронзы. Для получения такой структуры применяются различные квазистатические методы интенсивной пластической деформации (ИПД): сдвиг под высоким квазигидростатическим давлением, равноканальное угловое прессование (РКУП), всестороннюю осадку и др. [3-9]. Было установлено, что получение СМК структуры в сплавах на основе систем $\mathrm{Cu}-\mathrm{Cr}, \mathrm{Cu}-\mathrm{Zr}$ и $\mathrm{Cu}-\mathrm{Cr}-\mathrm{Zr}$ квазистатическими методами ИПД и проведение последующего старения приводит к их значительному упрочнению [4-10].

В настоящем исследовании использован новый способ ИПд - динамическое канально-угловое прессование (ДКУП) [11], представляющий собой высокоскоростной $\left(10^{4}-10^{5} \mathrm{c}^{-1}\right)$ вариант РКУП. Преимущество метода ДКУП заключается в использовании энергии пороховых газов вместо энергоемкого прессового оборудования, кратковременности ( 500 мкс) одного цикла прессования и возможности получения объемных СМК металлов и сплавов за два-четыре прохода [12-16]. Важно подчеркнуть, что деформация простого сдвига, форми- 
рующая структуру при РКУП, в случае ДКУП является высокоскоростной, кроме того, при ДКУП действует высокоскоростная ударно-волновая деформация сжатия.

В работе [15] было установлено влияние степени деформации при ДКУП и температуры последующего отжига на распад $\alpha$-твердого раствора и рекристаллизацию $\mathrm{Cu}-0,09 \mathrm{Cr}-0,08 \mathrm{Zr}$ бронзы. На примере $\mathrm{Cu}-0,14 \mathrm{Cr}-0,04 \mathrm{Zr}$ бронзы было показано, что ДКУП приводит к большей диспергизации и разориентировке фрагментов структуры, а следовательно, к более существенному повышению микротвердости по сравнению с интенсивной квазистатической деформацией [16]. Цель настоящей работы - исследование механических свойств и структуры низколегированной хромоциркониевой бронзы с субмикрокристаллической структурой, полученной высокоскоростной деформацией методом ДКУП.

\section{2. Материал и методика исследования}

Заготовки сплава $\mathrm{Cu}-0,14 \% \mathrm{Cr}-0,04 \% \mathrm{Zr}$ (мас. \%). были закалены от температуры $1000{ }^{\circ} \mathrm{C}$ в ледяную соленую воду. Из них были приготовлены цилиндрические образцы длиной 65 мм, диаметром 16 мм для деформирования методом ДКУП [11] в четыре прохода (маршрут $\mathrm{B}_{\mathrm{c}}$ ). За один проход истинная деформация составляла $e \approx 1,15$ [3], общая деформация была $e \approx 4,6$. Деформированный образец был разрезан вдоль по средней плоскости. Половина образца была разрезана на отдельные заготовки для исследования процесса старения и измерений микротвердости. Старение предварительно закаленных и деформированных заготовок проводили в интервале температур $300-700{ }^{\circ} \mathrm{C}$ в течение 1 ч. Отдельные опыты были выполнены после старения в течение 4 ч. Структурные исследования проводили на оптическом микроскопе EPYTIP-2 и на просвечивающем микроскопе JEM 200CX при напряжении 160 кВ. Микротвердость измеряли на приборе ПМТ-3 при нагрузке 0,49 Н, время выдержки при нагрузке составляло 5 с. Структурные исследования и измерение микротвердости проводили на продольной плоскости деформированного образца. Из другой половины деформированного методом ДКУП образца и из закаленной заготовки были вырезаны пластины толщиной 2,5 мм. Пластины были состарены при температурах, соответствующих максимуму микротвердости состаренных заготовок, а именно: при температуре $400{ }^{\circ} \mathrm{C}$ в течение 1 и 4 ч, $450{ }^{\circ} \mathrm{C}$ в течение 1 ч. Плоские разрывные образцы длиной 25 мм и рабочим сечением 2,0×1,5 мм были приготовлены из пластин шлифовкой с охлаждением. Испытания на растяжение при комнатной температуре со скоростью деформирования $1 \mathrm{~mm} / \mathrm{Mин} \mathrm{проводили}$ на машине INSTRON 3382. Предел прочности, предел текучести и относительное удлинение определяли по диаграммам растяжения.

\section{3. Результаты исследования и их обсуждение}

На рис. 1 представлены зависимости микротвердости хромоциркониевой бронзы от температуры старения закаленных (кривая 1) и деформированных образцов (кривая 2). Повышение микротвердости закаленных образцов начинается после старения при $400{ }^{\circ} \mathrm{C}$. После старения при $450{ }^{\circ} \mathrm{C}$ микротвердость имеет максимальное значение, 1030 МПа. ДКУП повышает величину микротвердости бронзы на 850 МПа по сравнению с закаленным состоянием. На рис. 1 (кривая 2) видно, что повышение микротвердости при старении в деформированном состоянии начинается при температуре старения $350{ }^{\circ} \mathrm{C}$. После старения при 400-450 ${ }^{\circ} \mathrm{C}$ микротвердость достигает максимального значения, равного 1700 МПа. В интервале температур старения 500-600 ${ }^{\circ} \mathrm{C}$ наблюдается резкое падение микротвердости. Таким образом, деформация методом ДКУП ускоряет процесс старения бронзы, что можно объяснить влиянием деформации на зарождение и кинетику выделения упрочняющих частиц. После деформации методом ДКУП микротвердость бронзы возрастает при старении в меньшей степени, чем при старении исходно закаленного состояния (на 150 и 280 МПа соответственно). Это указывает на прохождение начальных стадий распада $\alpha$-твердого раствора уже в ходе высокоскоростной деформации в процессе ДКУП.

Frolova N. Yu. et al. / Influence of aging and strain on the structure and mechanical properties of chromium- 


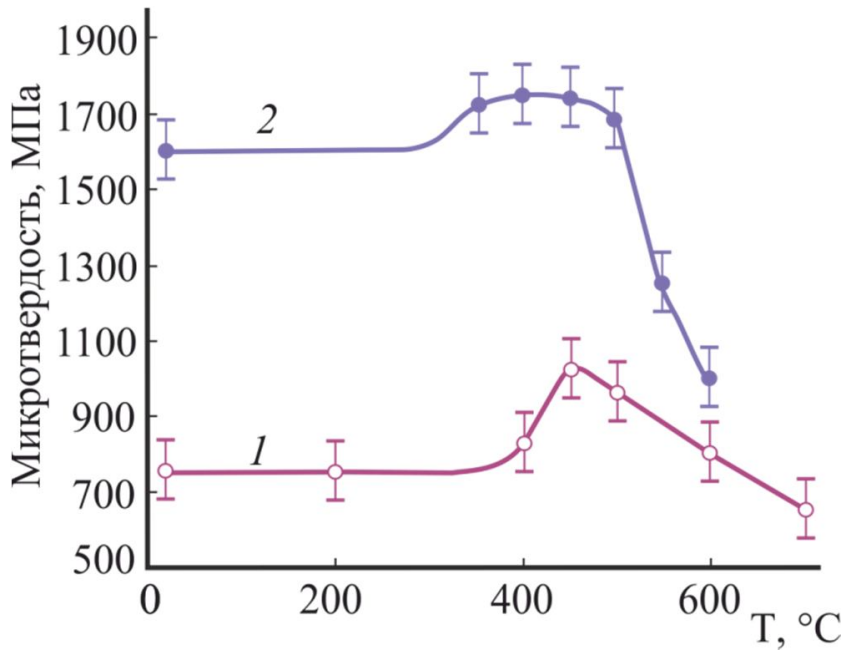

Рис. 1. Зависимость микротвердости бронзы от температуры старения в закаленном состоянии (кривая 1) и после деформации (кривая 2). Время выдержки 1 ч

В закаленном состоянии бронза имеет крупное зерно, размерами 200-300 мкм, с двойниками отжига.

Процесс выделения частиц при старении был исследован методами электронной микроскопии. Выделившиеся в исходно закаленном состоянии частицы наблюдаются лишь после старения при температуре $500{ }^{\circ} \mathrm{C}$. Выделение частиц $\mathrm{Cr}$ происходит гомогенно, на этой стадии частицы имеют ГЦК структуру, как это было показано в работе [15]. На электронограммах присутствуют рефлексы от ГЦК хрома. Размер частиц, определенный по темнопольным изображениям, составляет от 4 до 10 нм. Кроме частиц $\mathrm{Cr}$ обнаружено присутствие частиц закиси меди $\mathrm{Cu}_{2} \mathrm{O}$. Повышение температуры старения до $600{ }^{\circ} \mathrm{C}$ приводит к тому, что размер частиц хрома увеличивается до 10-15 нм. На рис. 2 а представлено светлопольное изображение и микродифракция исследованного сплава после закалки и отжига при $600{ }^{\circ} \mathrm{C}$. Около частиц хрома виден контраст в виде «кофейного зерна» (указан стрелками на рис. 2 a). На микродифракции присутствуют рефлексы ГЦК меди, ОЦК хрома и ГЦК закиси меди $\mathrm{Cu}_{2} \mathrm{O}$. Темнопольное изображение частиц $\mathrm{Cr}$ и закиси меди $\mathrm{Cu}_{2} \mathrm{O}$, представленное на рис. 2 , получено в близко расположенных рефлексах и $(01 \overline{1})_{\mathrm{Cr}}$, ось зоны [111] ОЦК и $(\overline{1} 1 \overline{1})_{\text {Си2о, ось }}$ зоны [110] ГЦК (рефлексы указаны стрелками на рис. 2 a).

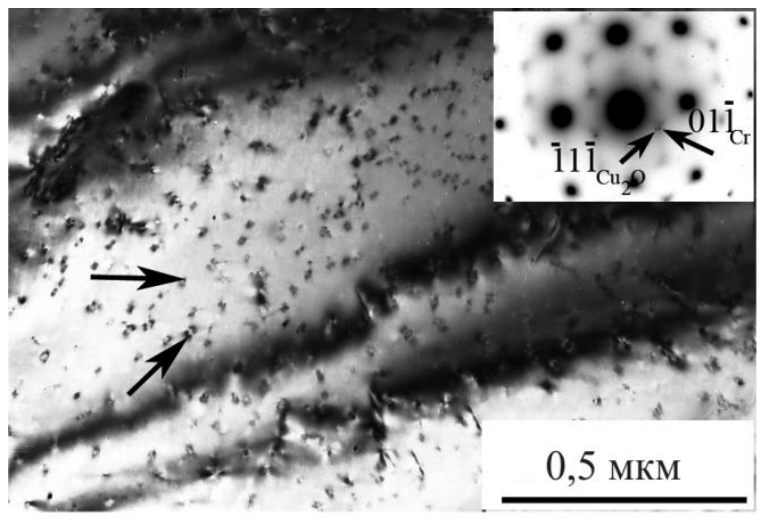

$a$

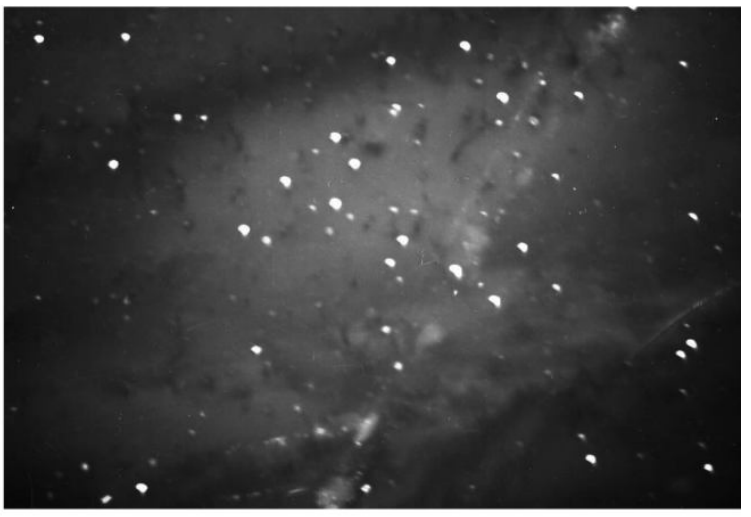

6

Рис. 2. Структура бронзы после закалки и старения при $600{ }^{\circ} \mathrm{C}$.

Светлопольное изображение (a); темнопольное изображение частиц $\mathrm{Cr}$ и закиси

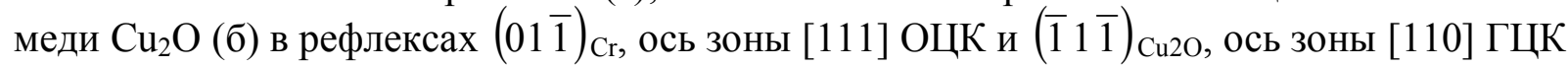


Необходимо отметить, что несмотря на то, что типы кристаллических решеток хрома и закиси меди разные и межплоскостные расстояния хрома $((011) \mathrm{Cr}(0,2052$ нм) и закиси меди (111) $\mathrm{Cu}_{2} \mathrm{O}(0,2450$ нм) отличаются, рефлекс от плоскости (011) $\mathrm{Cr}$, ось зоны [111] ОЦК и рефлекс от плоскости (111) $\mathrm{Cu}_{2} \mathrm{O}$, ось зоны[110]ГЦК на микродифракции располагаются близко.

Падение микротвердости при температуре старения $600{ }^{\circ} \mathrm{C}$ (рис. 1, кривая 1 ) указывает на то, что максимальные напряжения, создаваемые частицами $\mathrm{Cr}$ (10-15 нм) с когерентными границами, уменьшаются. Малый размер частиц фазы выделения связан с малым количеством легирующих элементов $\mathrm{Cr}$ и $\mathrm{Zr}$.

ДКУП значительно измельчает структуру хромоциркониевых бронз $[15,16]$. Металлографическое исследование показало, что на продольном сечении образца после четырех проходов ДКУП наблюдаются полосы локализованного течения, возникшие при последнем проходе прессования, и дисперсная структура, состоящая из деформированных зерен/субзерен. Полосы локализованного течения располагаются под углом $30-40^{\circ}$ к оси цилиндрического образца. Подобные структуры наблюдались в титане, меди и алюминиевых сплавах, подвергнутых ДКУП [12-15]. В образцах титана ВТ1-0 в полосах локализованного течения наблюдали рекристаллизацию $[12,13]$, в образцах из бронзы $[15,16]$ рекристаллизация отсутствовала, что связано с высокой теплопроводностью последних.

Электронно-микроскопическое исследование бронзы после ДКУП показало, что структура состоит из субзерен размером 100-200 нм, возникших в результате деформации и динамической полигонизации (рис. 3). Субзерна имеют удлиненную форму; внутри них формируются слабо разориентированные субзерна менышего размера - субзерна второго порядка (рис. 3 в). На границах субзерен виден контраст в виде отдельных темных точек и штрихов (указан стрелками на рис. 3 б), свидетельствующий о начальных стадиях распада твердого раствора. Высокоскоростная деформация при ДКУП приводит к нагреву образца, особенно в местах локализованного течения. Большая плотность дефектов кристаллического строения и повышение температуры создают условия для прохождения начальных стадий распада твердого раствора. Образование дисперсных (2-4 нм) частиц, во-первых, повышает предел текучести, во-вторых, задерживает формирование центров рекристаллизации при последующем нагреве. Старение деформированной бронзы при $400{ }^{\circ} \mathrm{C}$ в течение 1 ч приводит к образованию многочисленных чрезвычайно дисперсных (размером в несколько нанометров) частиц на границах и в объеме субзерен. Увеличение времени выдержки до 4 ч при этой температуре приводит к тому, что в отдельных крупных субзернах появляется контраст от фазы выделения в виде темных точек. Отметим также появление отдельных рекристаллизованных зерен размером 150 нм. Повышение температуры старения до $450{ }^{\circ} \mathrm{C}$ (выдержка 1 ч) приводит к формированию отчетливо видимого контраста по границам субзерен; внутри больших субзерен появляется контраст от частиц, расположенных вдоль границ субзерен второго порядка (указан стрелками на рис. $4 a$ ).

Старение при температуре $500{ }^{\circ} \mathrm{C}$ вызывает развитие рекристаллизации и небольшое снижение микротвердости. В структуре можно наблюдать рекристаллизованные зерна, растущие в область деформированной матрицы. В рекристаллизованных зернах крупные частицы Cr расположены вдоль бывших границ субзерен, а между ними наблюдаются очень мелкие частицы, возникшие, очевидно, гомогенно при более высокой температуре старения (рис. 4 б). При дальнейшем повышении температуры старения до 550 и $600{ }^{\circ} \mathrm{C}$ интенсивно развиваются процессы рекристаллизации и роста частиц до размеров 10-30 нм. Это приводит к снижению микротвердости сплава до 1200 и 1000 МПа (рис. 1, кривая 2).

Таким образом, основной вклад в упрочнение при старении исследованной бронзы вносят частицы фаз выделения, преимущественно частицы Cr. Сегрегации Zr, закрепляя дислокации, замедляют процессы возврата и рекристаллизации при последующем нагреве [15]. Средний размер частиц $\mathrm{Cr}$ составляет 10-15 нм даже при температуре старения $600{ }^{\circ} \mathrm{C}$. 
open-access journal

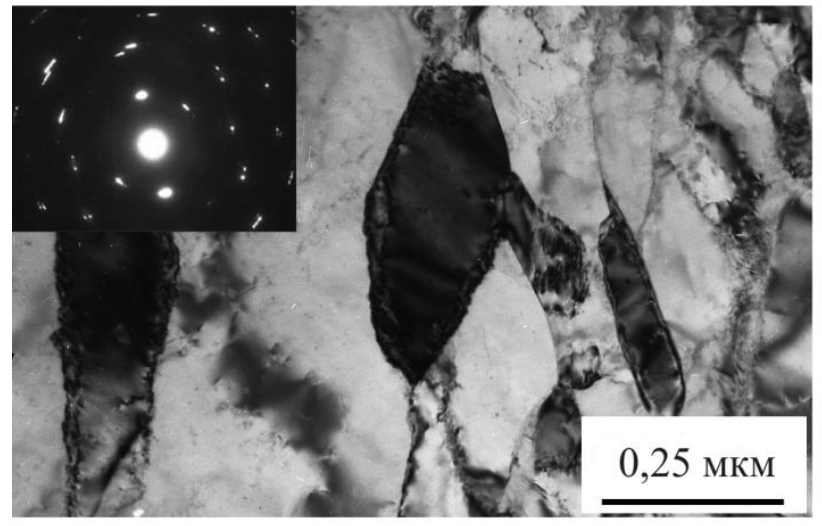

$a$

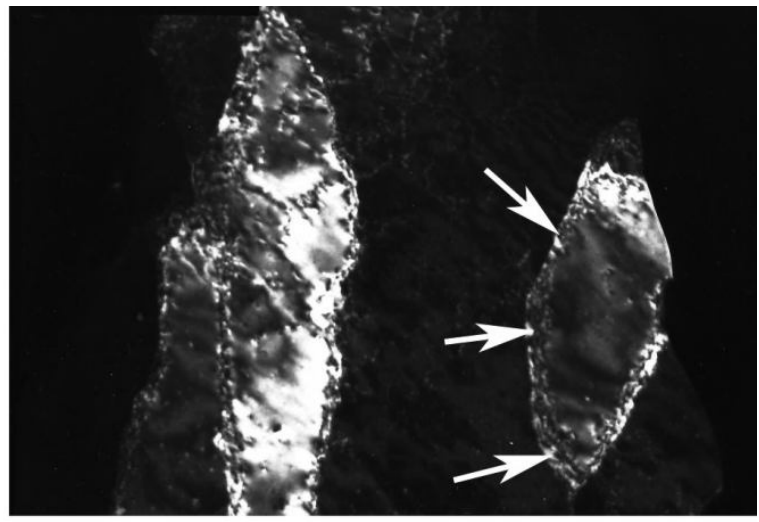

6

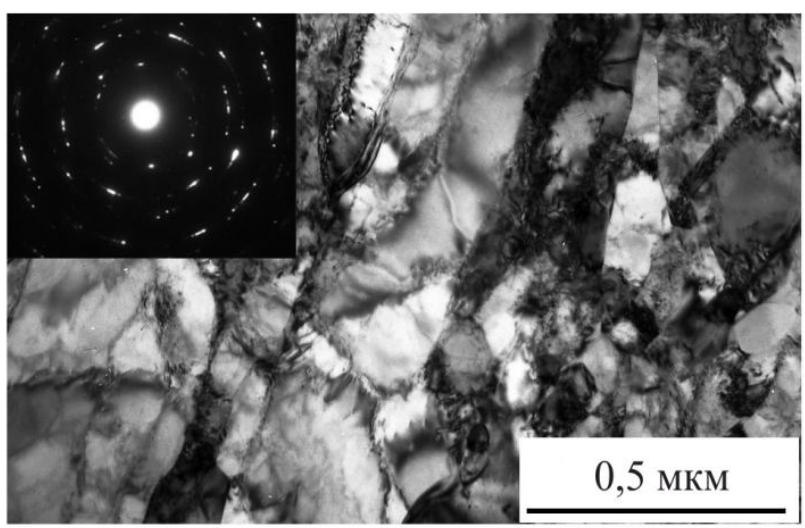

B

Рис. 3. Субзеренная структура бронзы после ДКУП.

Светлопольные изображения $(a, b)$; темнопольное изображение субзерен и частиц в совмещенном рефлексе матрицы и частиц $\mathrm{Cr}(б)$

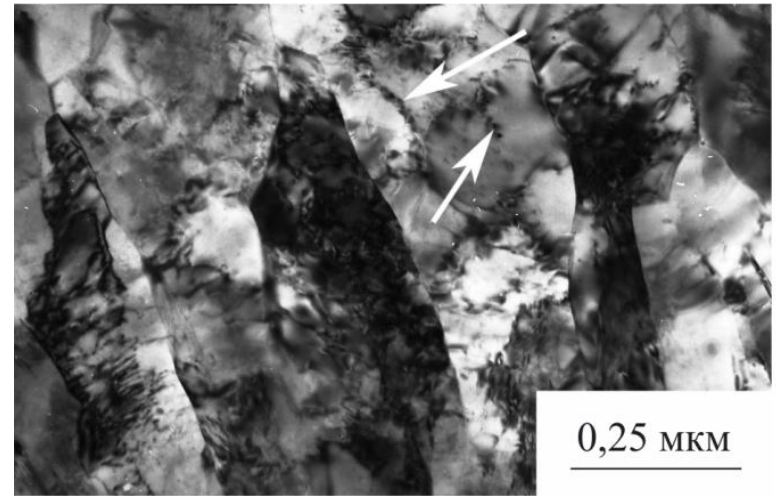

$a$

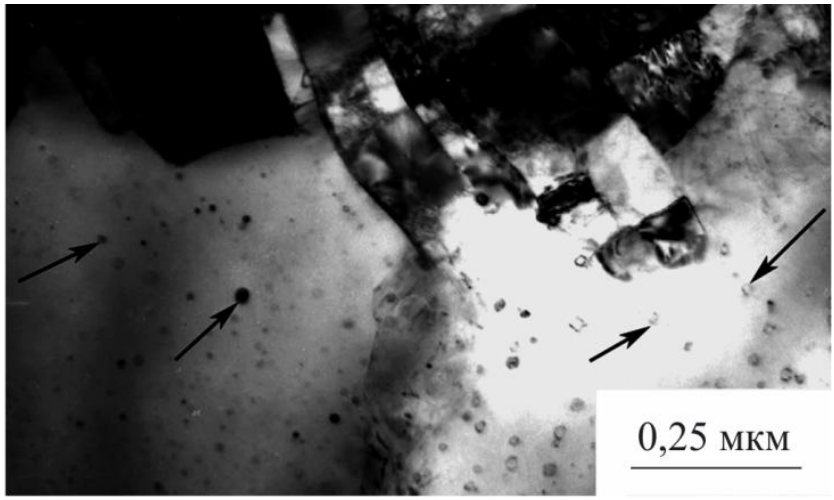

б

Рис. 4. Структура бронзы после ДКУП и старения при температурах $450{ }^{\circ} \mathrm{C}(a)$ и $550{ }^{\circ} \mathrm{C}($ б); $a$ - выделение частиц по границам субзерен; $\sigma$ - рост рекристаллизованного зерна в деформированную матрицу и частицы $\mathrm{Cr}$ в рекристаллизованном зерне

Рассмотренные структурные изменения в бронзе, а также изменение микротвердости при ДКУП и последующем старении, позволили подобрать оптимальный режим термообработки для получения наилучших механических свойств при испытаниях на растяжение. Сводные данные по механическим свойствам представлены в таблице. 
Механические свойства хромоциркониевой бронзы при испытаниях на растяжение

\begin{tabular}{|c|c|c|c|c|}
\hline $\begin{array}{l}\text { № } \\
\Pi / \Pi\end{array}$ & Обработка & $\sigma_{0,2}, \mathrm{M \Pi а}$ & $\sigma_{\mathrm{B}}, \mathrm{M \Pi а}$ & $\delta, \%$ \\
\hline 1 & \multirow{2}{*}{$\begin{array}{l}\text { Закалка от } 1000{ }^{\circ} \mathrm{C} \text { в ледяную соленую } \\
\text { воду }\end{array}$} & 95 & 198 & 38 \\
\hline 2 & & 93 & 195 & 36 \\
\hline 3 & \multirow[t]{2}{*}{ Закалка + старение при $450^{\circ} \mathrm{C}, 1$ ч } & 135 & 226 & 16 \\
\hline 4 & & 143 & 248 & 19 \\
\hline 5 & \multirow[t]{2}{*}{ Закалка + ДКУП 4 прохода } & 315 & 510 & 10,6 \\
\hline 6 & & 309 & 503 & 9,4 \\
\hline 7 & \multirow{2}{*}{$\begin{array}{l}\text { Закалка + ДКУП + старение при } \\
400{ }^{\circ} \mathrm{C}, 1 \text { ч }\end{array}$} & 462 & 545 & 11 \\
\hline 8 & & 465 & 538 & 9,8 \\
\hline 9 & \multirow{2}{*}{$\begin{array}{l}\text { Закалка + ДКУП + старение при } \\
400{ }^{\circ} \mathrm{C}, 4 \text { ч }\end{array}$} & 442 & 551 & 12 \\
\hline 10 & & 485 & 521 & 13,5 \\
\hline 11 & \multirow{2}{*}{$\begin{array}{l}\text { Закалка + ДКУП + старение при } \\
450{ }^{\circ} \mathrm{C}, 1 \text { ч }\end{array}$} & 474 & 519 & 9,4 \\
\hline 12 & & 480 & 520 & 12 \\
\hline
\end{tabular}

В закаленном состоянии образцы имеют низкие значения предела текучести (94 МПа) и предела прочности (196 МПа) и высокую пластичность, 37 \%. Старение закаленных образцов при температуре $450{ }^{\circ} \mathrm{C}$ в течение 1 ч приводит к повышению предела текучести на 45 МПа, предела прочности на 40 МПа. Повышение прочностных характеристик связано с выделением частиц хрома, сохраняющих когерентную связь с матрицей [15]. ДКУП сплава в четыре прохода повышает предел прочности в 2,6 раза, предел текучести в 3,3 раза, по сравнению с закаленным состоянием. Пластичность сплава остается на достаточно высоком уровне и составляет $10 \%$. Значительное повышение прочностных характеристик после ДКУП обусловлено следующими факторами. Во-первых, сильно фрагментированная структура, полученная при ДКУП в четыре прохода, содержит большую плотность границ субзерен, которые являются препятствием для движения дислокаций. Во-вторых, легирующие элементы $\mathrm{Cr}$, особенно $\mathrm{Zr}$, имеющие малую растворимость в меди, образуют при высокоскоростной деформации сегрегации на дефектах кристаллического строения. Старение при температуре $400{ }^{\circ} \mathrm{C}$ в течение 1 ч приводит к возрастанию предела прочности до $541 \mathrm{MПа,} \mathrm{пре-}$ дела текучести - до 463 МПа. Предел текучести сплава увеличивается по сравнению с закаленным состоянием почти в 5 раз. Небольшое увеличение предела прочности деформированных образцов при старении, на 40 МПа, может быть, связано с тем, что еще при ДКУП произошли начальные стадии выделения частиц, а при старении при $400{ }^{\circ} \mathrm{C}$ происходит рост ранее выделившихся по границам субзерен частиц хрома. Увеличение времени выдержки при этой температуре до 4 часов не приводит к повышению предела прочности и предела текучести. Повышение температуры старения до $450{ }^{\circ} \mathrm{C}$ в течение 1 ч уменьшает предел прочности на 20 МПа, предел текучести существенно не изменяется. Заметим, что для достижения практически таких же механических свойств в промышленной бронзе $\mathrm{Cu}-0,5 \% \mathrm{Cr}-0,12 \% \mathrm{Ag}$ за счет РКУП понадобилось 8 проходов [10].

\section{4. Выводы}

Установлено существенное повышение механических свойств $\mathrm{Cu}-0,14 \% \mathrm{Cr}-0,04 \% \mathrm{Zr}$ бронзы после ДКУП и после ДКУП и последующего старения при температурах 400-450 ${ }^{\circ} \mathrm{C}$ : предел прочности увеличивается в 2,6 и 2,8 раза, предел текучести - в 3,3 и 5,1 раза соответственно, по сравнению с исходным закаленным состоянием при сохранении удовлетворительной пластичности.

Показано, что высокий уровень механических свойств и термическая стабильность при 400-500 ${ }^{\circ} \mathrm{C}$ исследуемой низколегированной бронзы, подвергнутой ДКУП, обусловлены Frolova N. Yu. et al. / Influence of aging and strain on the structure and mechanical properties of chromium- 
значительным деформационным упрочнением и деформационным старением с выделением наноразмерных частиц упрочняющих фаз.

Сравнительное исследование механических свойств и структуры бронзы после закалки и старения и после ДКУП и старения позволило разделить влияние деформации и влияние старения на механические свойства и на процесс распада твердого раствора.

\section{Благодарность}

Электронно-микроскопическое исследование выполнено на оборудовании центра коллективного пользования в Испытательном центре нанотехнологий и перспективных материалов ИФМ УрО РАН.

Работа выполнена в рамках государственного задания по теме «Структура» № 01201463331 и при частичной финансовой поддержке проекта УрО РАН № 15-17-2-24.

\section{Литература}

1. Сварка в машиностроении. Справочник. Т. 1 / Под ред. Н. А. Ольшанского. - М. : Машиностроение, 1978. - 504 с.

2. Осинцев О. Е., Федоров В. Н. Медь и медные сплавы. Отечественные и зарубежные марки. Справочник. - М. : Машиностроение, 2004. - 336 с.

3. Валиев Р. 3., Александров И. В. Объемные наноструктурные металлические материалы: получение, структура и свойства. - М. : ИКЦ «Академкнига», 2007. - 398 с.

4. Structure and Properties of ultra-fine grain $\mathrm{Cu}-\mathrm{Cr}-\mathrm{Zr}$ alloy produced by equal-channel angular pressing / A. Vinogradov, V. Patlan, G. Suzuki, K. Kitagawa, V. I. Kopylov // Acta Materialia. - 2002. - Vol. 50, iss 7. - P. 1639-1651. - DOI: 10.1016/S1359-6454(01)00437-2.

5. Shan'gina D. V., Bochvar N. R., Dobatkin S. V. Structure and properties of Cu-Cr alloys subjected to shear under pressure and subsequent heating // Russian Metallurgy (Metally). - 2010. Vol. 2010, iss. 11. - P. 1046-1052. - DOI: 10.1134/S0036029510110091.

6. Behavior of an ultrafine-grained $\mathrm{Cu}-\mathrm{Zr}$ alloy in heating / D. V. Shan'gina, Yu. M. Maksimenkova, N. R. Bochvar, S. V. Dobatkin // Russian Metallurgy (Metally). - 2011. Vol. 2011, iss. 11. - P. 1069-1073. - DOI: 10.1134/S0036029511110085.

7. Impact of the deformation-heat treatment on the mechanical and functional properties of $\mathrm{Cu}-\mathrm{Cr}-\mathrm{Zr}$ alloy / L. F. Sennikova, A. A. Davidenko, V. Z. Spuskaniuk, V. Yu. Dmitrenko, T. A. Zakoretskaya // Scientific and Technical Journal "Voprosy Materialovedeniya". - 2013. No. 4 (76). - P. 35-42.

8. Мелехин Н. В., Чувильдеев В. Н. Влияние равноканально-углового прессования на процесс выделения частиц в сплаве $\mathrm{Cu}-\mathrm{Cr}-\mathrm{Zr} / /$ Физика твердого тела. Вестник Нижегородского университета им. Лобачевского. - 2011. - № 5 (1). - С. 55-61.

9. Grain refinement in a $\mathrm{Cu}-\mathrm{Cr}-\mathrm{Zr}$ alloy during multidirectional forging / I. Shakhova, Z. Yanushkevich, I. Fedorova, A. Belyakov, R. Kaibyshev// Materials Science and Engineering: A. - 2014. - Vol. 606. - P. 380-389. - DOI: 10.1016/J.MSEA.2014.03.116.

10. Islamgaliev R. K., Nesterov K. M., Valiev R. Z. Structure, strength, and electric conductivity of a $\mathrm{Cu}-\mathrm{Cr}$ copper-based alloy subjected to severe plastic deformation // The Physics of Metals and Metallography. - 2015. - Vol. 116, iss. 2. - P. 209-218. - DOI: 10.1134/S0031918X14090063. 11. Способ динамической обработки материалов: пат. 2283717. Рос. Федерация / заявитель, патентообладатель Шорохов Е. В., Жгилев И. Н., Валиев Р. 3. - № 2004131484/02 ; заявл. 28.10.04 ; опубл. 27.04.06, бюл. № 26. - 64 с.

12. High-strain-rate deformation of titanium using dynamic equal-channel angular pressing / V. I. Zel'dovich, N. Yu. Frolova, I. N. Zhgilev, A. E. Kheifets, I. V. Khomskaya, V. M. Gundyrev // The Physics of Metals and Metallography. - 2008. - Vol. 105, iss. 4. - P. 402-408. DOI: $10.1134 / \mathrm{S} 0031918 \mathrm{X} 08040145$. 
13. Structure of titanium after dynamic channel angular pressing at elevated / V. I. Zel'dovich, E. V. Shorokhov, N. Yu. Frolova, I. N. Zhgilev, A. E. Kheifets, I. V. Khomskaya, P. A. Nasonov, A. A. Ushakov // The Physics of Metals and Metallography. - 2009. - Vol. 108, iss. 4. P. 347-352. - DOI: 10.1134/S0031918X09100044.

14. Formation of a submicrocrystalline structure upon dynamic deformation of aluminum alloys / I. G. Brodova, I. G. Shirinkina, O. V. Antonova, E. V. Shorokhov // Materials Science and Engineering A. - 2009. - Vol. 503. - P. 103-105. - DOI: 10.1016/j.msea.2007.12.060.

15. Structure of chromium-zirconium bronze subjected to dynamic channel-angular pressing and aging / V. I. Zel'Dovich, I. V. Khomskaya, N. Y. Frolova, A. E. Kheifets, E. V. Shorokhov, P. A. Nasonov // The Physics of Metals and Metallography. - 2013. - Vol. 114, iss. 5. P. 411-418. - DOI: 10.1134/S0031918X13050141.

16. Structure and microhardness of chromium-zirconium bronze subjected to severe plastic deformation by dynamic channel-angular pressing and rolling / G. V. Zel'dovich, N. Yu. Frolova, I. V. Khomskaya, A. E. Kheifets, E. V. Shorokhov, P. A. Nasonov // The Physics of Metals and Metallography. - 2014. - Vol. 115, iss. 5. - P. 465-470. - DOI: 10.1134/S0031918X14050159. 